\title{
Cytology- A useful diagnostic tool in ascites, 2 years study
}

\author{
Goyal S. ${ }^{1}$, Shah N. ${ }^{2}$, Shah F.R ${ }^{3}$, Shah J.M ${ }^{4}$. \\ ${ }^{1}$ Dr. Sunita C. Goyal, ${ }^{2}$ Dr. Nilay L. Shah, ${ }^{3}$ Dr. F.R. Shah, ${ }^{4}$ Dr. J.M. Shah, ${ }^{1,2}$ Assistant Professor, Department of \\ Pathology, GMERS Medical College, Himmatnagar. ${ }^{3}$ Associate Professor, ${ }^{4}$ Professor \& H.O.D. AMC MET Medical \\ College Maninagar, Ahmedabad, Gujarat 380008.
}

Corresponding Author: Dr. Nilay Shah, Pathology Department, GMERS Medical College, Himmatnagar, Gujarat, India. E-mail id-dr.nilay2020@gmail.com

\begin{abstract}
Background: Identification of malignant cells in any body fluid always is a challenging task for cytopathologist. Detailed clinical history, morphological evaluation and sometimes modern techniques like cytochemistry and immunohistochemistry can help us whenever required. Ascites is a common clinical finding with a wide range of etiology. Ascites is defined as collection of excessive fluid in the peritoneal cavity. The present study aims to note down various pathological findings in Transudative and Exudative ascites. This will help the clinician, surgeon and oncologist in treating the patient and it is the determining factor for treating patient. Materials and Methods: It is an observational, prospective study. 120 cases of ascitic fluid cytology were collected from the patients admitted in a tertiary care hospital which is situated in Ahmedabad over a period of 2 years. Detailed examination- physical, biochemical and microbiological (wherever indicated) was done along with cytology examination of ascitic fluid. Result: We studied 120 cases of ascitic fluid cytology. Most common causes of ascitic fluid effusion after examining 120 cases were liver cirrhosis followed by tuberculosis, inflammatory, malignant, acute bacterial infection, cardiac and renal causes. Among malignant effusion GIT and ovary were most common primary site of malignancy and commonest malignancy was adenocarcinoma. Conclusion: Definite diagnosis of ascitic fluid effusion can be done in most of the cases by doing cytology and detailed examination like physical, biochemical and microbiological examination of that fluid. However in some cases newer techniques like cytochemistry and immunohistochemistry may require for confirmation. Cytology is first line of investigation along with other radiological investigation to rule out neoplastic lesions. It is also useful in identification of non neoplastic lesions like tuberculosis, Cirrhosis of liver, Nephrotic Syndrome, congestive cardiac failure, Anaemia- Hypoproteinemia \& Spontaneous bacterial peritonitis. It helps clinician in management of patients.
\end{abstract}

Keywords: Ascitic fluid, Cytology, Malignant cells

\section{Introduction}

There are three serosal body cavities in our body. They are pleural, peritoneal and pericardial cavity. These serous cavities are lined by outer parietal and inner visceral layer of epithelium [1]. Normally they contain very little amount of lubricating fluid which is up to 50 $\mathrm{ml}$ required for lubricating underlying viscera. Accumulation of fluid is known as effusion which occurs when there is imbalance between fluid formation and removal [2].

The name "ascites" is derived from the Greek word known as 'Askitos' meaning bladder or bag and defined as pathologic accumulation of fluid within the peritoneal cavity [3]. Paracentesis is the procedure in which peritoneal cavity is perforated with a hollow

Manuscript received: $4^{\text {th }}$ February 2019

Reviewed: $12^{\text {th }}$ February 2019

Author Corrected: $17^{\text {th }}$ February 2019

Accepted for Publication: $21^{\text {st }}$ February 2019 needle to remove fluid or gas. Paracentesis with ascitic fluid analysis is the most rapid, simple, safe \& costeffective method of determining the etiology of ascites. Ascitic fluid effusion is classified into transudate and exudate. Transudate is watery and has low protein and very scanty cellularity, on the other end exudates is thick and has high protein as well as high cellularity. Transudateeffusion occurs due to either increased hydrostatic pressure or due to decrease oncotic pressure.

Common Causes of transudative effusion are cirrhosis, congestive heart failure, constrictive pericarditis, hepatic vein obstruction (Budd-Chiari syndrome), portal vein obstruction, Nephrotic syndrome, malnutrition, protein losing enteropathy. Exudative effusion is mostly due to inflammatory origin. Common causes of Exudative effusion in ascites are tuberculosis, bacterial infection of GIT viscera, trauma, secondary peritoneal 
Original Research Article

carcinomatosis, lymphomas, leukemia, primary hepatic tumor, mesotheliomas etc. The differentiation of the fluid into malignant or non-malignant fluid is the main aim for cytology examination and it has a deep impact on treating patients. Exfoliative cytology for fluid is highly specific though less sensitive to detect malignancy [4].

Apart from help in cancer detection, it also helps regarding systemic pathology and various inflammatory conditions of the peritoneal cavity. In cytology of nonmalignant effusion, we can see number of cells like mesothelial cells, neutrophils, eosinophils, lymphocytes, macrophages, plasma cells.

The diagnosis of tumor types, such as adenocarcinomas, squamous carcinomas, tumors with endocrine functions, malignant lymphomas or sarcomas in effusions, is of significant clinical value in case of malignant effusion because it helps clinician or surgeon to locate primary site for tumor and has deep impact on management of patients.

\section{Objectives}

a. To differentiate ascitic fluid effusion in to inflammatory, neoplastic, infective or immune mediated lesions.

b. To assess the proportion of neoplastic and non neoplastic condition causing ascitic fluideffusion.

c. To study the pattern of effusions in various neoplastic and non neoplastic conditions.

\section{Materials \&Methods}

It is observational, prospective study over a period of 2 years and carried out at our hospital. Paracentesis was performed by clinician.

We received 120 cases of ascitic fluid effusion for cytology at our pathology department along with pretested proforma, which include clinical findings, clinical diagnosis \& other supportive investigations. Sample was received in sterile plastic container.

All samples were examined for physical, biochemical and microbiological examination along with cytology. From the received fresh sample, $5 \mathrm{ml}$ fluid was taken and fluid was centrifuged at $2500 \mathrm{rpm}$ for 15 minutes and a minimum of four thin smears were prepared from the sediment and were immediately fixed in $95 \%$ alcohol and stained with $\mathrm{H} \& \mathrm{E}$ stain. Other stains like Giemsa stain was used whenever required.

Physical examination includes various features like volume, color, odour, $\mathrm{Ph}$, specific gravity. The biochemical examination of ascitic fluid includes estimation of glucose level, proteins level and adenosine deaminase.

Total WBC count and RBC count of fluid was carried out using Neubauer's chamber with the help of WBC diluting fluid.

The sediment, smears were prepared and stained by field's and leishman stain for differential count. For hemorrhagic fluids, glacial acetic acid was used as a haemolysing agent and after that they were processed.

After confirming final diagnosis, each data was analysed.

Study site- The study was conducted at the central laboratory, Pathology Department, N.H.L. Medical College, Ahmedabad.

Duration of study was 2 years.

Study design- Observational prospective study.

Case selection- The study was carried out on all samples clinically diagnosed as Ascites.

Inclusion criteria: All samples clinically diagnosed as Ascites and received in sterile container.

Exclusion Criteria: Samples which were less than 5 $\mathrm{ml}$, not received in sterile container were excluded for study.

Sample size- Sample size of present study is 120 .

Ethical permission-Permission was taken from Institutional Ethics Committee to conduct this study.

Statistical Analysis: The data was analysed using the Microsoft Excel 2007.

\section{Results}

Total 120 cases of ascites were studied. Age range in our study was 01-89 years. Table 1 shows distribution of cases by age and sex. Maximum number of cases $36(30 \%)$ was found in the age group $41-50$ followed by 30 cases $(25 \%)$ in the age group 51-60years. 
Table-1: Distribution of cases by age and sex.

Original Research Article

\begin{tabular}{|c|c|c|c|c|c|c|}
\hline \multirow[t]{2}{*}{ Age groups } & \multicolumn{2}{|c|}{ Male } & \multicolumn{2}{|c|}{ Female } & \multirow[t]{2}{*}{ Total } & \multirow[t]{2}{*}{$\%$} \\
\hline & Total No & $\%$ & Total No & $\%$ & & \\
\hline $0-10$ & 00 & 0.00 & 00 & 0.00 & 00 & 0.00 \\
\hline $11-20$ & 03 & 4.60 & 02 & 3.63 & 05 & 4.16 \\
\hline $21-30$ & 05 & 7.60 & 07 & 12.72 & 12 & 10.00 \\
\hline $31-40$ & 10 & 15.30 & 06 & 10.90 & 16 & 13.33 \\
\hline $41-50$ & 20 & 30.70 & 16 & 29.09 & 36 & 30.00 \\
\hline $51-60$ & 16 & 24.60 & 14 & 25.45 & 30 & 25.00 \\
\hline $61-70$ & 07 & 10.70 & 07 & 12.72 & 14 & 11.60 \\
\hline $71-80$ & 03 & 4.60 & 02 & 3.63 & 05 & 4.16 \\
\hline $81-90$ & 01 & 1.50 & 01 & 1.81 & 02 & 1.66 \\
\hline Total & 65 & 100.0 & 55 & 100.0 & 120 & 100 \\
\hline
\end{tabular}

We found 65 cases of male while 55 cases of female with male to female ratio was 1.18:1.

Out of total 120 cases, 12 cases were of neoplastic effusion while 108 cases were of non-neoplastic effusion. Liver cirrhosis $(53.3 \%)$ was the leading cause for non-neoplastic effusion followed by renal causes $(11.6 \%)$.

Table-2: Etiology wise distribution of cases.

\begin{tabular}{|c|c|c|}
\hline Etiology & Total No & \% \\
\hline Liver Cirrhosis & 64 & 53.30 \\
\hline Anemia-Hypoproteinemia & 12 & 10.00 \\
\hline Renal causes & 14 & 11.60 \\
\hline Congestive Cardiac failure & 04 & 3.30 \\
\hline Malignancy & 12 & 10.00 \\
\hline Tuberculosis & 10 & 8.33 \\
\hline Idiopathic & 04 & 3.30 \\
\hline Total & $\mathbf{1 2 0}$ & $\mathbf{1 0 0}$ \\
\hline
\end{tabular}

102 cases were found to be transudates and 18 cases were of exudates. Transudates comprised cases of liver cirrhosis (53.3\%), nephrotic syndrome (11.6\%), anemia-hyporoteinemia $(10 \%)$ and CCF $(3.3 \%)$. Exudates comprised cases of tuberculosis $(8.3 \%)$, malignancy $(10 \%)$ and subacute bacterial peritonitis.

Table-3: Distribution of neoplastic ascitic fluid effusion with primary identified.

\begin{tabular}{|c|c|c|}
\hline Primary Site of malignancy & No & \% \\
\hline GIT & 4 & 33.3 \\
\hline Ovary & 3 & 25.0 \\
\hline NHL & 1 & 8.3 \\
\hline Unknown & 4 & 33.3 \\
\hline
\end{tabular}

Out of 12 cases of malignant effusion, GIT was the most common site for primary tumor with 4 cases $(33.3 \%)$ followed by ovary 3 cases $(25.0 \%)$. In 4 cases primary site was not identified.
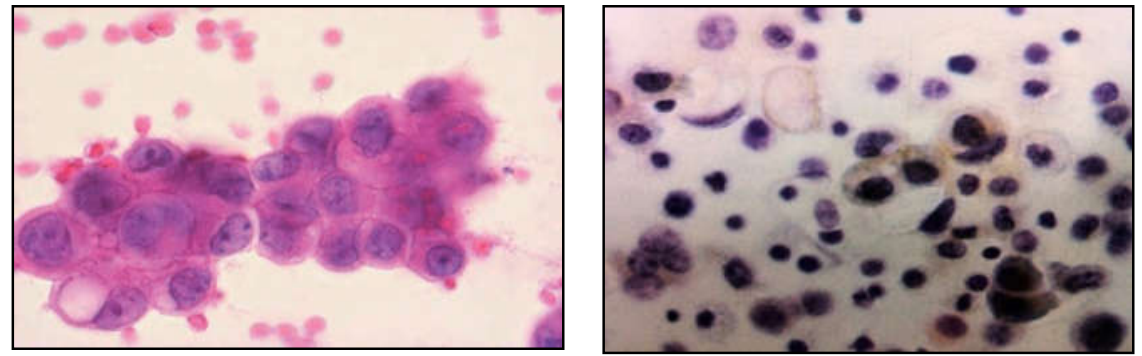

Fig 1 \& 2: Metastatic Adenocarcinoma (H \& E stain)

Ascitic fluid: Signet ring formation in metastatic Gastric Carcinoma (H\&E stain) 

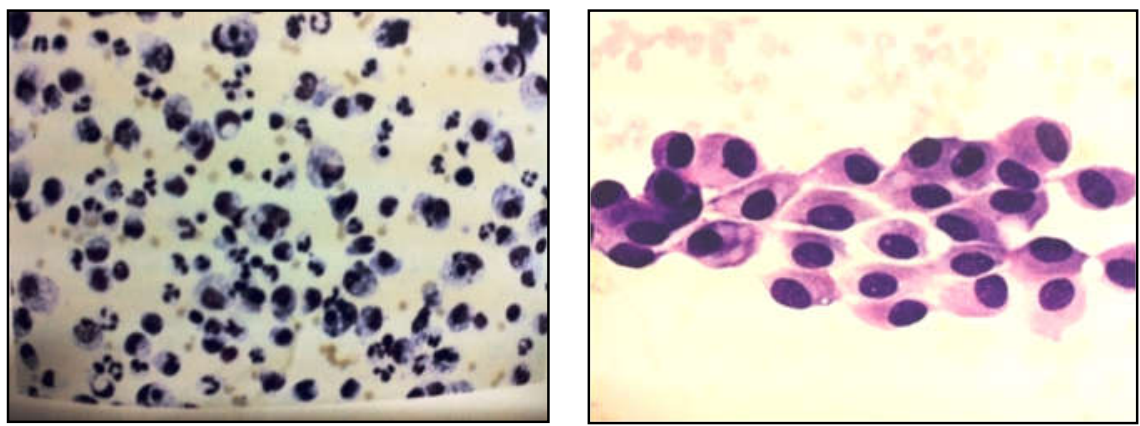

Fig 3 \& 4: Acute Suppurative inflammation (H\& E Stain), Sheets of mesothelial cells (H \& E stain),

\section{Discussion}

Diagnostic cytology is the scientific art of interpretation of cells from the human body that exfoliate or are removed from their physiologic millieu. Cytodiagnosis of ascitic fluid represents the cell population from a much larger representative area than that obtained from needle biopsy [5]. Mechanism of formation of abnormal amount of fluid in a body cavity can be explained by 'Starlings Law' which states that fluid are accumulated when there is a decrease in the plasma colloidal pressure and increased capillary hydrostatic pressure [6].

The cytological examination of ascitic fluid has an important role in diagnosing the cause of ascites like [7]
A. Malignancy- (a) primary - mesotheliomas or (b) Secondary- metastasis, lymphomas and leukemias.
B. Specific chronic inflammatory conditions- tuberculosis.
C. Non-specific chronic inflammatory conditions.
D. Acute purulent ascites - acute appendicitis, acutepancreatitis.
E. Parasites - microfilaria in endemic areas.
F. Connective tissue disorders.

It is important to distinguish malignancy related ascites from non-malignant ascites since their management modalities are not the same. It is even worse to assume a malignancy is absent, when it is actually present in a patient simply due to poor diagnostic ability of cytology. Since about $10 \%$ of all ascites are of malignant origin, there is need for accurate diagnosis to be made because of the metastatic effect of malignancies. Accurate and early diagnosis would go long way in forestalling the complications associated with malignancies. The present study deals with the accuracy of diagnosis on the basis of contemporary cytological features,cell count and biochemical features. The advantages of cytology is that it is a relatively simple, rapid, inexpensive and less invasive tool having a high accuracy with low incidence of false positive diagnosis.

In our study, We found 65 cases of male while 55 cases of female with male to female ratio was 1.18:1 which is comparable to studies carried out by Khan \& Mahmood et al[8,9].

Out of 120 cases, 108 cases were of non neoplastic effusion and 12 cases were of malignant effusion. Common cause for non neoplastic effusion was liver cirrhosis accounting $53.3 \%$ total cases which is comparable with study carried out by Chung ES et al [10].

The incidence of nephrotic syndrome (11.6\%), anaemia hypoproteinemia (10\%) and CCF (4\%) are slightly higher than studies carried by Jain SC and Nath K.[11,12]. Incidence of malignant effusion in our study was $10 \%$ which was comparable to KhanT.H et al study [13].

Out of total 102 transudates, 73 cases showed lymphocyte predominance effusion, 16 cases showedMesothelial predominance and 11 cases showed neutrophils predominance effusion.

Out of 18 cases of nonneoplastic exudates, tuberculous effusion was most common accounting 12 cases $(66.66 \%)$ which are comparable to study carried out by Malabuetal [14]. 
Original Research Article

The most common primary site in cases of malignant effusion was GIT with 4 cases (33.33\%) followed by 3 cases (25\%) of Ovary while in 4 cases we could not find primary site which are comparable with studies carried out by Sears DHaidu [15], Lopez \& Cardoz [16] and Khan et al [17]. About 8 cases (66.6\%) of malignant effusion were hemorrhagic which was comparable to studies carried out by Jain SC and Nath K [11,12]. It is worth to note that all hemorrhagic fluids need not be due to malignancy and non-hemorrhagic fluids can have malignant cells.

Table-4: Primary site of malignancy in cases of malignant effusion (In various study).

\begin{tabular}{|c|c|c|c|c|c|c|c|}
\hline Sr No & Study & $\begin{array}{c}\text { Ovary } \\
\mathbf{\%}\end{array}$ & $\begin{array}{c}\text { GIT } \\
\mathbf{\%}\end{array}$ & $\begin{array}{c}\text { Lung } \\
\mathbf{\%}\end{array}$ & $\begin{array}{c}\text { Breast } \\
\mathbf{\%}\end{array}$ & $\begin{array}{c}\text { Others } \\
\mathbf{\%}\end{array}$ & $\begin{array}{c}\text { Unknown } \\
\mathbf{\%}\end{array}$ \\
\hline 1 & Sears DHaidu [15] & 24 & 19 & 5 & 4 & 29 & 19 \\
\hline 2 & Lopez \& Cardoz [16] & 16 & 21 & 4 & 3 & 07 & 49 \\
\hline 3 & Khan et al[17] & 12 & 69 & 0 & 0 & 0 & 19 \\
\hline 4 & Present study & 25 & 33.3 & 0 & 0 & 0 & 33.3 \\
\hline
\end{tabular}

Commonest malignancy metastasizing to peritoneal cavity was adenocarcinomas followed by Non Hodgk in lymphoma.

Out of 12 cases of malignant effusion, male to female ratio was 1.4:1 with 7 cases were found in male and 5 cases were found in female. Maximum number of malignant effusions was found in the age group of $41-60$ years ( 5 case).

Malignant cells have moderate cytoplasm and hyperchromatic, pleomorphic nuclei with prominent nucleoli and form gland like structures with central lumina. They form 3 dimensional and complex papillary clusters. Some of the cases showed binucleate cells and multinucleate giant cells. Malignant cells have Irregular nuclear membranes, nuclear moulding and absence of "windows", these features differentiate them from mesothelial cells.

Overall, the present study showed that, fluid cytology is very useful in classifying benign conditions, further it plays a very useful role in rapid diagnosis of malignant effusions. Fluid cytology although not a substitute for conventional histopathology but as complementary to it and is useful in categorizing benign conditions as well as in the diagnosis of malignant conditions.

Ascitic fluid Adenosine Deaminase (ADA) nowadays widely used for confirmation of tuberculosis inflammation in case of lymphocyte rich effusion while fluid protein and fluid LDH are used for diagnosis of exudates.

Cytospin and cell block techniques are very helpful in rising cell yield of ascitic fluid effusions and guarantee high diagnostic value particularly when cellularity is low. They even have advantage of higher preservation of cellular morphology compare to traditional technique.

In difficult cases like adenocarcinomas and malignant mesothelioma newer techniques like immunohistochemistry may have useful role.Calretinin, CK 5/6 and WT1 are useful mesothelial markers while, CEA, B72.3 and Ber- EP4are useful markers for adenocarcinomas.

\section{Conclusion}

This study is conducted to evaluate efficacy of cytological examination ofascitic fluid in various disease and we found that confirmative diagnosis of ascitic fluid effusion can be achieved by cytological analysis along with physical, biochemical and microbiological examination in most of the cases. In difficult cases newer techniques like cytochemistry, immunohistochemistry may find useful. Thus, Ascitic fluid cytology is a very cost effective first line of investigation and important to clinician for early diagnosis, staging, and prognosis of disease and helpful in management of patients.

\section{Contribution from the author}

- Dr. Sunita Goyal: Data collection, analysis and preparation of manuscript.

- Dr. Nilay Shah: Analysis and preparation of manuscript \& critical revision.

Findings: Nil; Conflict of Interest: None initiated Permission from IRB: Yes

\section{References}

1. Nguyen GK. Essentials of fluid cytology. Gia-Khanh Nguyen; 2010. 
2. Kumavat PV, Kulkarni MP, Sulhyan KR. Cytological study of Effusions. Indian Medical Gazette. 2013; August: 306-313

3. Turnage RH. Abdominal wall, umbilicus, peritoneum, mesenteries, omentum, and retroperitoneum. Sabiston textbook of surgery. 2008: 1150-1.

4. Runyon BA. Care of patients with ascites. N Engl J Med. 1994 Feb 3;330(5):337-42.

5. Shobha SN, Kodandaswamy CR. Utility of modified cell block technique in cases of pleural effusion suspected of malignancy. Int J Health Sci Res. 2013;3 (1): 33-8.

6. Zocchi L. Physiology and pathophysiology of pleural fluid turnover. Eur Respir J. 2002 Dec;20(6):1545-58.

7. Culling CF, Allison RT, Barr WT. Cytology technique. cellular pathology technique. 4th edn. London: Butterworth and Co.(Publishers) Ltd. 1985; 336.

8. Khan FY. Ascites in the state of Qatar: aetiology and diagnostic value of ascitic fluid analysis. Singapore Med J. 2007 May;48(5):434-9.

9. Mahmood G, Debnath CR, Mandal AK. Evaluation of 100 cases of ascites. Mymensingh Med J. 2009 Jan;18(1):62-6.

10. Chung ES, Eun SJ, Song KE, Suh JS, Lee WK, Kim JS. Diagnostic value of cholesterol and triglyceride in pleural andascitic fluid. Korean Journal of Clinical Pathology. 1992 Sep 1;12(3):291-8.

11. Jain SC, Misra SM, Misra NP, et al. Diagnostic value of ascitic fluid examination. J Assoc Physicians India. 1966 Jan;14(1):59-69.

12. Nath K, Mital HS, Mishra SD, et al. Diagnostic value of ascitic fluid examination. J Assoc Physicians India. 1968 Dec;16(12):991-6.

13. Khan TH, Durrani HA, Shah SN. Evaluation of peritoneal biopsy and ascitic fluid examination in the etiological diagnosis of ascites. J Assoc Physicians India. 1976 Sep;24(9):579-86.

14. Malabu UH, Olubuyide IO, Shaibu ME, Olawuyi F. Ascites in Ibadan, Nigeria-usefulness of albumin gradient in its etiologic diagnosis. Biomedical Research. 2006;17:105-9.

15. Sears D, Hajdu SI. The cytologic diagnosis of malignant neoplasms in pleural and peritoneal effusions. Acta Cytol. 1987 Mar-Apr;31(2):85-97.

16. Cardozo PL. A critical evaluation of 3000 cytologic analyses of pleural fluid ascitic fluid and pericardial fluid. Acta Cytologica. 1966 Jan 1;10(6):455.

17. Khan N, Sherwani RK, Afroz N, Kapoor S. Cytodiagnosis of malignant effusion and determination of primary site. Journal of cytology. 2005 Jul 1;22 (3): 107.

\section{How to cite this article?}

Goyal S, Shah N, Shah F.R, Shah J.M. Cytology- A useful diagnostic tool in ascites, 2 years study. Trop J Path Micro 2019;5(2):94-99.doi:10.17511/jopm.2019.i02.08. 